\title{
Some Physiological and Ethological Effects of Nicotine; Studies on the Ant Myrmica sabuleti as a Biological Model
}

\author{
Marie-Claire Cammaerts ${ }^{1}$, Zoheir Rachidi ${ }^{1} \&$ Geoffrey Gosset ${ }^{1}$ \\ ${ }^{1}$ Zoheir Rachidi, Geoffrey Gosset, Faculté des Sciences, Université Libre de Bruxelles, Bruxelles, Belgium \\ Correspondence: Marie-Claire Cammaerts, Zoheir Rachidi, Geoffrey Gosset, Faculté des Sciences, Université \\ Libre de Bruxelles, Bruxelles, Belgium. E-mail: mtricot@ulb.ac.be
}

Received: July 1, 2014 Accepted: July 23, 2014 Online Published: August 1, 2014

doi:10.5539/ijb.v6n4p64 URL: http://dx.doi.org/10.5539/ijb.v6n4p64

\begin{abstract}
Nicotine is one of the most consumed alkaloids. Its effects still lead to mixed conclusions. Having recently observed that ants could be used as biological models, we examined several physiological and ethological effects of nicotine using the ant Myrmica sabuleti as a biological model. We pointed out that nicotine increases the individuals' locomotion, decreases the precision of their reaction, decreases their response to pheromones, does not impact their audacity, and reduces their food consumption. Nicotine largely decreases the individuals' learning abilities when the reward does not contain this alkaloid but increases the rapidness of acquiring visual as well as olfactory conditioning when the reward contains nicotine. In the latter case, the final conditioning score is only very slightly higher than the control score, and there is no memorization. Under nicotine consumption, ants' cognitive abilities seem of better quality, the ants in fact acting more rapidly. There is no habituation to nicotine consumption. No dependence on this alkaloid exists, as long as the individuals feel well, but dependence appears as soon as the individuals need something, are deprived of something. After nicotine consumption ends, a first slow, than a short rather quick, and finally again a slow decrease of its effects occurs. As for other alkaloids, no dependence is associated to no habituation and to rather slow vanishing of the effects. However, since the effects of nicotine quickly vanish during a short time, dependence might develop if the individual then encounters any problem or need. All the effects, here revealed using ants as biological models, are in agreement with those actually known for nicotine. Some effects could even be better defined, i.e. the impact on cognition, the occurrence of dependence. The present work brings so some new information about this important alkaloid and shows, once more, that ants could be used as biological models, for a first, not expensive step of a more general, biological or medical study.
\end{abstract}

\section{Introduction}

Nicotine is one of the most consumed, and the most easily available alkaloid in the word. It can be consumed by inhalation, ingestion or contact. Several effects due to nicotine consumption are known (Waldum et al., 1996; Frenk \& Dar, 2005; Mayer, 2013). For instance, it is known that this alkaloid has an effect on the brain, acts rapidly and imitates acetylcholine, what induces feeling some satisfaction, some well-being. It is commonly admitted that nicotine has an anti-depressive action, helps reducing anxiousness, stimulates the brain functioning and may act as an appetite suppressant. It might lead to dependence, this being yet controversy, and the underlying mechanisms being not yet entirely elucidated. Substances are often added to products containing nicotine in order to increase this potential dependence. All the effects of nicotine are probably not yet known, and all of them are probably not related to people. Scientific experiments on several living organisms are lacking, though a lot of invertebrates and vertebrates can be used, as biological models, for studying biological problems (Kolb \& Wishaw, 2002; Wehner \& Gehring, 1999; Deutsch, 1994; Devineni \& Heberlein, 2013; Russell \& Burch, 2014). Among the invertebrates, insects, and especially social hymenoptera, are advantageously used as biological models (Andre, Wirtz, \& Das, 1989; Doring \& Chittka, 2011). Among others, bees are often used (for instance, Abramson, Wells, \& Janko, 2007). We have recently shown that ants could be used as biological models for examining some physiological and ethological effects of elements, treatments, and factors (Cammaerts, Rachidi, Bellens, \& De Doncker, 2013, Cammaerts \& Gosset, 2014, Cammaerts, Rachidi, \& Gosset, 2014). Indeed, several nests, with hundreds of ants, can easily be maintained in laboratories, at low cost and very conveniently, throughout the entire year. These insects are highly evolved as for their morphology, their physiology, their social organization and their behavior. They have a unique resting position of their labium, mandibles and maxilla (Keller, 2011a, b), and numerous 
glands emitting efficient compounds (Billen \& Morgan, 1998). Their societies are highly organized with a strong division of labor, an age-based polyethism and social regulation (Hölldobler \& Wilson, 1990). Their behavior is incomparable: they care for their brood, build sophisticated nests, chemically mark the inside of their nest, and, differently, their nest entrances, their nest surroundings and their foraging area (Passera \& Aron, 2005). They generally use an alarm signal, a trail pheromone, and a recruitment signal (Passera \& Aron, 2005); they are able to navigate using memorized visual and olfactory cues (cf. Cammaerts, 2012, Cammaerts \& Rachidi, 2009; Cammaerts, Rachidi, Beke, \& Essaadi, 2012a); they efficiently recruit nestmates where, when and as long as it is necessary (Passera, 2006), and, finally, they provide their area with cemeteries (Keller \& Gordon, 2006). We have already largely studied the species Myrmica sabuleti Meinert 1861. Among others, we actually know its ecology, eye morphology, visual perception, visual and olfactory conditioning, navigation system, recruitment strategy, responses to pheromones, acquisition by callow ants of adults' cognitive abilities (Cammaerts \& Cammaerts, 2014; Cammaerts et al., 2013; Cammaerts, 2013 a, b, 2014, in press). Consequently, we aimed to study, on M. sabuleti, as many effects of nicotine as we could, in order to known some more about this alkaloid, and to check again the potential use of ants as biological models. More precisely, we intended to examine if nicotine impacts the individuals' activity, behavior, audacity, food consumption, learning capability, memory, and cognitive ability, and in which circumstances these physiological and ethological functions may be affected. We also wanted to precise if nicotine leads to habituation, and/or to dependence (addiction) and, if so, in which circumstances. A last objective would be defining the decrease of the effects of nicotine after its consumption ends. According to the experience we have about $M$. sabuleti, we thought being able to achieve the here above enumerated objectives. We planned several observations, on a few nests, but must then make checking and supplementary experiments consequently to first results. Here, we present the carried out experiments, the obtained results, and the deducting conclusions and thought.

\section{Functions examined and carried out experimental planning.}

\subsection{Functions}

The effect of nicotine on the following physiological and ethological functions was examined:

- the individuals' general activity, via their locomotion, and more precisely their linear and their angular speed.

- the precision of their reaction via their orientation towards a source of their alarm signal

- their response to their pheromone via their trail following behavior

- their audacity via the numbers of them coming onto a risky apparatus

- their consumption of food via the number of them eating meat food

- their learning and memory abilities via their acquisition of visual and olfactory conditioning, and their retaining of the acquired conditioning

- their habituation to nicotine consumption via their locomotion after 7 days of nicotine consumption

- their dependence on nicotine via the numbers of them preferring food containing this alkaloid

- a cognitive ability requiring no memory via their behavior in an adequate experimental apparatus

- the decrease, with time, of the effects of nicotine, by assessing the ants' orientation to an alarm signal, in the course of time, after the alkaloid had been removed from the food.

\subsection{Experimental Planning}

The following experiments were performed, in such an order for obtaining adequate controls, testing not yet experimented individuals, checking first results and looking for complementary ones. Details are given below, in the 'Material and Methods' section, but let us already inform that six ant nests (labeled I to VI) were used, nests I and II for control and test experiments, nests III and IV for test experiments, and nests V and VI for control experiments.

- control experiments were made on nests I and II fed with lactose solution: the ants' locomotion, orientation, trail following behavior, audacity, and food consumption were assessed; visual and olfactory conditioning, and memory, were assessed, the reward being the meat food free of nicotine; habituation to and dependence on lactose were examined.

- test experiments were made on nests I and II fed with lactose + nicotine solution: the ants' locomotion, orientation, trail following behavior, audacity, and food consumption were assessed; the ants' habituation to and dependence on nicotine were examined. 
- test experiments were made on nests III and IV fed with lactose + nicotine solution: the ants' visual and olfactory conditioning, and memory, were assessed, the reward being the meat food free of nicotine; the ants' dependence on nicotine was examined.

- an ants' ability requiring no memory was assessed on nests I and II fed with nicotine, and on nests V and VI having never received this alkaloid.

- test experiments were made on nests III, IV, I and II fed with lactose + nicotine solution: the ants' visual (on nests III and IV) and olfactory (on nests I and II) conditioning, and memory, were assessed, the reward being the sugar food containing nicotine.

- the decrease of the effects of nicotine was examined on nests I and II by assessing, in the course of time, the ants' orientation to an alarm signal, once the ants stopped eating nicotine.

\section{Material and Methods}

\subsection{Collection and Maintenance of Ants}

The study was made on six colonies of $M$. sabuleti collected, in summer 2013, in an old quarry located at Treigne (Ardenne, Belgium). The ants were nesting under stones, on a field covered with small, often odorous plants. The six collected colonies were demographically identical, containing about 600 workers, one or two queens and brood (at larval stage). They were maintained in the laboratory in artificial nests made of one to three glass tubes half-filled with water, with a cotton-plug separating the ants from the water. The glass tubes were deposited in trays $(34 \mathrm{~cm} \times 23 \mathrm{~cm} \times 4 \mathrm{~cm}$ ), the sides of which were covered with talc to prevent the ants from escaping. The trays served as foraging areas, food being delivered into them (Figure 1A). The ants were fed with sugar-water provided ad libitum in a small glass tube plugged with cotton, and with cut Tenebrio molitor larvae (Linnaeus, 1758) provided twice a week on a glass slide. Temperature was maintained between $18^{\circ} \mathrm{C}$ and $22^{\circ} \mathrm{C}$, humidity at about $80 \%$, these conditions remaining constant over the course of the study. Lighting had a constant intensity of 330 lux while caring for the ants, training and testing them. During other time periods, the lighting was dimmed to 110 lux. The electromagnetic field had an intensity of $2-3 \mu \mathrm{W} / \mathrm{m}^{2}$.

\subsection{Acquisition of the Alkaloids; Realization of Aqueous Solutions for Ants}

One gram of lactose and 15 gram of lactose (8) + nicotine (2) were provided, via the pharmacist Mr. Cardon J. (1050, Brussels), by the manufacturer UNDA dolisos (1140, Brussels). The two products were provided as a white bright powder, at the highest level of purity possible. Using a precise balance, $60 \mathrm{mg}$ of lactose, as well as $75 \mathrm{mg}$ of lactose (8) + nicotine (2), were prevailed and dissolved in $15 \mathrm{ml}$ of a saturated solution of brown sugar, the ants' common liquid food. The concentration in nicotine of the solution was thus $15 \mathrm{mg}$ in $15 \mathrm{ml}$, so $1 / 1,000$. These solutions were given to the ants, like their usual liquid food, in a small glass tube plugged with cotton, this cotton being refreshed each two days.

\subsection{Assessment of the Ants' Linear Speed, Angular Speed and Orientation}

Ants' linear and angular speed was assessed for detecting excitation in the animals. This assessment was made on ants freely moving on their foraging area. Ants' orientation towards an isolated congener's head (the source of the ants' alarm pheromone) was assessed for examining the ants' precision of reaction. An isolated worker's head, with widely open mandibles, is a source of alarm pheromone identical to that of an alarmed worker, in terms of the dimensions of the emitting source (the mandibular glands opening) and the quantity of pheromone emitted (Cammaerts-Tricot, 1973).

Each time, such assessment was made on ants of two colonies having never consumed nicotine but being fed with the solution of lactose, then on ants of these two same colonies having consumed the solution of lactose + nicotine during two days. For each assessment, the movement of 10 ants of each two colonies ( $\mathrm{N}=20$ ants) was analyzed.

Trajectories were recorded manually, using a water-proof marker pen, on a glass slide placed on the top of the experimental tray, set horizontally $3 \mathrm{~cm}$ above the area where the tested individuals were moving. A metronome set at 1 second was used as a timer for assessing the total time of each trajectory. Each trajectory was recorded during 5 to 10 seconds or until the ant reached the stimulus. All the trajectories were then traced (copied) with a water-proof marker pen onto transparent polyvinyl sheets (Figure $1 \mathrm{~B}, \mathrm{C}$ ). These sheets could then be affixed to a PC monitor screen. The trajectories were then analyzed using specifically designed software (Cammaerts, Morel, Martino \& Warzée, 2012b). Briefly, each trajectory was defined in the software by clicking as many points as needed with the mouse. Then, the total time of the trajectory (assessed using the metronome) was entered, and feature of the trajectory could be measured (linear speed, angular speed, orientation).

The three variables used to characterize the trajectories were defined as follows: 
The linear speed $(\mathrm{V})$ of an animal is the length of its trajectory divided by the time spent moving along this trajectory. It was measured in $\mathrm{mm} / \mathrm{s}$.

The angular speed (S) (i.e. the sinuosity) of an animal's trajectory is the sum of the angles, measured at each successive point of the trajectory, made by the segment 'point $\mathrm{i} \rightarrow$ point $\mathrm{i}-1$ ' and the segment 'point $\mathrm{i} \rightarrow$ point $\mathrm{i}+$ 1', divided by the length of the trajectory. This variable was measured in angular degrees $/ \mathrm{cm}$.

The orientation $(\mathrm{O})$ of an animal towards a given point (here an empty piece of paper or an ant's head) is the sum of the angles, measured at each successive point of the registered trajectory, made by the segment 'point $i$ of the trajectory $\rightarrow$ given point' and the segment 'point $\mathrm{i} \rightarrow$ point $\mathrm{i}+1$ ' divided by the number of measured angles. This variable was measured in angular degrees. When such a variable $(\mathrm{O})$ equals $0^{\circ}$, the observed animal perfectly orients itself towards the point; when $\mathrm{O}$ equals $180^{\circ}$, the animal fully avoids the point; when $\mathrm{O}$ is lower than $90^{\circ}$, the animal has a tendency to orient itself towards the point; when $\mathrm{O}$ is larger than $90^{\circ}$, the animal has a tendency to avoid the point.

Each distribution of 20 variables was characterized by its median and its quartiles since it was not Gaussian (Table 1 , lines 1,2$)$, and the distribution of values obtained for ants having consumed alkaloid was statistically compared to that previously obtained for the ants having never consumed alkaloid using the non-parametric $\chi^{2}$ test (Siegel \& Castellan, 1989, p 111-116). The significance threshold was set to $\alpha=0.05$.

Table 1. Effect of nicotine on five physiological and ethological functions

\begin{tabular}{|c|c|c|c|c|}
\hline Functions & Variable assessed & No nicotine & + nicotine & Statistics \\
\hline Activity $\mathrm{n}=20$ & Linear speed $\mathrm{mm} / \mathrm{sec}$ & $17.4(14.5-20.2)$ & $20.9(20.1-23.5)$ & $\mathrm{P}<0.001$ \\
\hline (locomotion) & Sinuosity ang.deg./cm & $107(86-119)$ & $129(109-152)$ & $\mathrm{P}=0.05$ \\
\hline $\begin{array}{l}\text { Precision of a reaction } \\
\mathrm{n}=20\end{array}$ & $\begin{array}{l}\text { Orientation to an alarm signal; } \\
\text { ang.deg. }\end{array}$ & $32.0(21.6-56.59)$ & $53.7(43.3-63.8)$ & $\mathrm{P} \approx 0.001$ \\
\hline Response to pheromones & Trail following behavior & C: $1(1-1.3)$ & $C: 1(1-2)$ & NS \\
\hline $\mathrm{n}=40$ & ( $n^{\circ}$ of arcs walked) & $\mathrm{T}: 12.0(8.8-17.3)$ & $\mathrm{T}: 6.5(3.0-9.3)$ & $\mathrm{P}<0.001$ \\
\hline Audacity $\mathrm{n}=10$ & $\mathrm{n}^{\circ}$ of ants on a tower & $1.3(1-2)$ & $1.6(0-3)$ & $\mathrm{P}=0.35$ \\
\hline $\begin{array}{l}\text { Food consumption } \\
\mathrm{n}=10\end{array}$ & $\begin{array}{c}\mathrm{n}^{\circ} \text { of ants eating meat (mean, } \\
\text { extremes) }\end{array}$ & $3.7(1-8)$ & $1.4(0-3)$ & $\mathrm{P}=0.05$ \\
\hline
\end{tabular}

Details are given in the text. Briefly, nicotine increased ants' linear and angular speed, unchanged their audacity, and decreased their precision of reaction, their response to pheromones as well as their food consumption.

\subsection{Assessment of the Ants' Trail Following Behavior}

This behavior was assessed for examining the ants' response to their pheromones. The trail pheromone of Myrmica ants is produced by the workers' poison gland. So, ten of these glands were isolated in $0.5 \mathrm{ml}(500 \mu \mathrm{l})$ hexane and stored for $15 \mathrm{~min}$ at $-25{ }^{\circ} \mathrm{C}$. To perform one experiment, $0.05 \mathrm{ml}(50 \mu \mathrm{l})$ of the solution was deposited, using a normograph pen (a pen used for drawing, hexane extract being poured inside the pen instead of ink), on a circle ( $\mathrm{R}$ $=5 \mathrm{~cm}$ ) pencil drawn on a piece of white paper and divided into $10 \mathrm{ang}$. deg. arcs. One minute after being prepared, the piece of paper with the artificial trail was placed in the ants' foraging area. When an ant came into contact with the trail, its movement was observed. Its response was assessed by the number of 10 ang. deg. arcs it walked without departing from the trail, even if it turned back on the trail. If an ant turned back when being in front of the trail, its response was assessed as "zero arcs walked"; when an ant crossed the trail without following it, its response equaled "one walked arc". Before testing the ants on a trail, they were observed on a circumference imbibed with $50 \mu 1$ of pure hexane and the control numbers of walked arcs were so obtained. For each control and test experiment, 20 individuals of each two used colonies were observed; 40 numbers of walked arcs were so each time recorded. Each distribution of values was characterized by its median and its quartiles, since it was not Gaussian (Table 1, line 3). The experiments were performed on two colonies fed with the solution of lactose, then on the two same colonies fed since three days with the solution of lactose + nicotine. The distributions of values obtained for ants having consumed nicotine were statistically compared to the corresponding ones obtained for ants having never consumed that substance, this by using the non parametric $\chi^{2}$ test (Siegel \& Castellan, 1989). On 
such experimental trails, Myrmica workers do not deposit their trail pheromone because they do so only after having found food or a new nest site.

\subsection{Assessment of the Ants' Audacity}

A tower built in strong white paper (Steinbach $\left.{ }^{\circledR}\right)(\mathrm{h}=4 \mathrm{~cm}$; diam=1.5cm) was set on the foraging area of two colonies fed with the solution of lactose, and then of the same two colonies fed during three days with the solution of lactose + nicotine (Figure $1 \mathrm{D}$ ). The ants present on the tower were counted 10 times. The mean and the extreme values of the obtained values were established each time and the two series of values were compared using the non parametric Mann-Whitney U test (Siegel \& Castellan, 1989, p 128-137; Table 1, line 4).

\subsection{Assessment of the Ants' Consumption of Food}

The observations were made on two colonies fed with the solution of lactose, and then on the two same colonies fed for five days with the solution of lactose + nicotine. Each time, the workers present on the T. molitor larva were counted 10 times. The numbers obtained under the two kinds of food consumption were statistically compared using the Mann-Whitney $U$ test (same reference as above) and the mean as well as the extreme values of the recorded numbers were established (Table 1, line 5).

\subsection{Assessment of the Ants' Ability in Acquiring Operant Either Visual or Olfactory Conditioning, and of the Ants' Either Visual or Olfactory Memory}

Briefly, at a given time, either a green hollow cube or pieces of thyme were set above the T. molitor larva, this time tied to the supporting piece of glass, or, in a checking experiment, either a yellow hollow cube or pieces of onion were set above or aside the sugar food containing nicotine. The ants so underwent, each time, either visual or olfactory operant conditioning. Each time, tests were performed, in the course of time, while the ants were expected acquiring conditioning, then, after having removed the green (or the yellow) cube or the pieces of thyme (or of onion), while the ants were expected partly losing their conditioning.

In detail, ants were collectively visually trained to a hollow green (or yellow) cube constructed of strong paper (Canson ${ }^{\circledR}$ ) according to the instructions given in Cammaerts and Nemeghaire (2012) and set over the meat food (or the sugar food) which served as a reward. The color has been analyzed to determine its wavelengths reflection (Cammaerts, 2007). The ceiling of each cube was filled unlike the four vertical faces, this allowing the ants entering the cubes. Choosing the green (or yellow) cube was considered as giving the 'correct' choice when ants were tested as explained below. The ants were olfactory conditioning by setting four pieces of thyme (or of onion) aside the tied dead T. molitor larvae (or the source of sugar food, respectively). Choosing the pieces of thyme (or of onion) was considered as giving the 'correct' choice when ants were tested as explained below

Ants were individually tested in a Y-shaped apparatus constructed of strong white paper according to the instructions given in Cammaerts, Rachidi and Cammaerts (2011), and set in a small tray (30 cm x $15 \mathrm{~cm} \mathrm{x} 4 \mathrm{~cm})$, apart from the experimental colony's tray (Figure 1A, E, F). Each colony had its own testing design. The apparatus had its own bottom and the sides were covered with talc to prevent the ants from escaping. In the Y-apparatus, the ants deposited no trail since they were not rewarded. However, they may utilize other chemical secretions as traces. As a precaution, the floor of each Y-apparatus was changed between tests. The Y-apparatus was provided with either a green (or yellow) cube, or four pieces of thyme (or of onion), in one or the other branch (Figure $1 \mathrm{E}, \mathrm{F}$ ). Half of the tests were conducted with the cube, or the odorous plant, in the left branch and the other half with the cube, or the odorous plant, in the right branch of the Y maze, and this was randomly chosen. Control experiments had previously been made on never conditioned ants. In the present work, conditioning experiments were made on ants of two colonies having never received nicotine but fed with the solution of lactose (see above), and on ants of two other, identical, collected colonies having received the solution of lactose + nicotine during seven days (Table 2). These experiments were made using green cubes and thyme. Then, when supplementary experiments had to be made, the same colonies were used but the cues were replaced by yellow cubes and onion. Indeed, once an animal is conditioned to a given stimulus, it becomes no longer naïve for such an experiment. It was thus impossible to perform, on the same ants, conditioning without then with nicotine; the only solution was to use four similar colonies, two for conditioning without nicotine, and two for conditioning under nicotine consumption. And after that, it was impossible to make a checking experiment on the same colonies using the same cues; the only solution was to perform identical experiments but with different (other color, other odor), though similar (cube, pieces), cues (Table 4). 

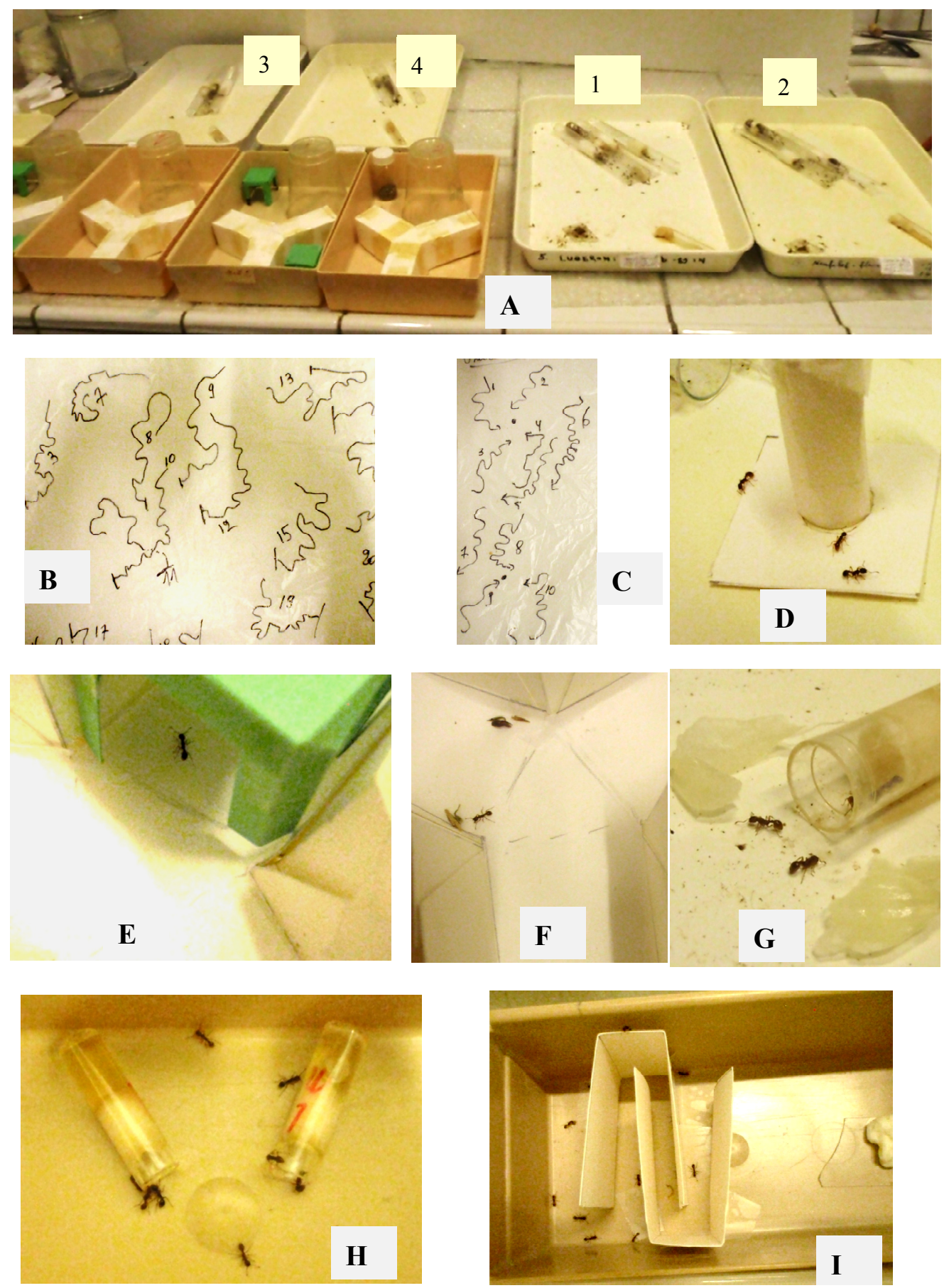

Figure 1. Some views of the experiments. A: four nests of Myrmica sabuleti used, and the Y mazes prepared for experimenting. B: ants' trajectories under nicotine consumption; the ants' linear and angular speed were large. C: ants trajectories, under nicotine consumption, in the vicinity of an alarm signal (the black points); not all the ants correctly moved towards the signal. D: ants, under nicotine consumption, confronted with a risky apparatus; as usual, the ants were not inclined to climb on the tower. $\mathbf{E}$ : an ant correctly responding to a green hollow cube, during a test in a $\mathrm{Y}$ maze. F: an ant correctly responding to thyme, during a test in a Y maze. G: ants, under nicotine consumption, trained to pieces of onion, and rewarded with sugar water containing nicotine. H: ants, under nicotine consumption, not hungry and feeling well, confronted with an aqueous solution of sugar + lactose and one of sugar + lactose + nicotine (on the right); the ants did not prefer the food containing nicotine; they were not dependent on that alkaloid consumption. I: ants, under nicotine consumption, tested in an apparatus made of a narrow loggia (on the left), a maze, and a large area (on the right); the ants, initially set in the narrow loggia, soon found their way through the maze, towards the large area 
Table 2. Effect of nicotine on conditioning acquisition and on memory, using meat food (free of nicotine) as a reward

\begin{tabular}{|c|c|c|c|c|c|}
\hline Studied function & no nicotine & & + nicotine & & statistics \\
\hline Visual learning ability & $* \mathrm{C}: 61 / 59$ & $50 \%$ & & & \multirow{10}{*}{$\mathrm{P}=0.016$} \\
\hline \multirow[t]{9}{*}{$\mathrm{n}=20+20=40$} & $7 \mathrm{hrs} 11 / 9$ & $55 \%$ & 7 hrs 11/9 & $55 \%$ & \\
\hline & 24 hrs $12 / 8$ & $60 \%$ & 24 hrs $12 / 8$ & $60 \%$ & \\
\hline & 30 hrs $12 / 8$ & $60 \%$ & 30 hrs $12 / 8$ & $60 \%$ & \\
\hline & 48 hrs $13 / 7$ & $65 \%$ & 48 hrs $12 / 8$ & $60 \%$ & \\
\hline & 55 hrs $13 / 7$ & $65 \%$ & 55 hrs $12 / 8$ & $60 \%$ & \\
\hline & 72 hrs $14 / 6$ & $70 \%$ & 72 hrs $12 / 8$ & $60 \%$ & \\
\hline & 79 hrs $13 / 7$ & $65 \%$ & 79 hrs $12 / 8$ & $60 \%$ & \\
\hline & 96 hrs $14 / 6$ & $70 \%$ & 96 hrs $12 / 8$ & $60 \%$ & \\
\hline & 103 hrs $13 / 7$ & $65 \%$ & 103 hrs $12 / 8$ & $60 \%$ & \\
\hline Visual memory & 7 hrs $13 / 7$ & $65 \%$ & $7 \mathrm{hrs} 11 / 9$ & $55 \%$ & \multirow{8}{*}{$\mathrm{P}=0.063$} \\
\hline \multirow{7}{*}{$\mathrm{n}=20+20=40$} & 24 hrs $15 / 5$ & $75 \%$ & 24 hrs 1010 & $50 \%$ & \\
\hline & 30 hrs $14 / 6$ & $70 \%$ & 30 hrs $10 / 10$ & $50 \%$ & \\
\hline & 48 hrs $14 / 6$ & $70 \%$ & $48 \mathrm{hrs} 10 / 10$ & $50 \%$ & \\
\hline & 55 hrs $14 / 6$ & $70 \%$ & & & \\
\hline & 72 hrs $14 / 6$ & $70 \%$ & & & \\
\hline & 79 hrs $14 / 6$ & $70 \%$ & & & \\
\hline & 96 hrs $14 / 6$ & $70 \%$ & & & \\
\hline Olfactory learning ability & * C: $61 / 59$ & $50 \%$ & & & \multirow{14}{*}{$\mathrm{P}=0.031$} \\
\hline \multirow[t]{8}{*}{$\mathrm{n}=20+20=40$} & $7 \mathrm{hrs} 11 / 9$ & $55 \%$ & 7 hrs $10 / 10$ & $50 \%$ & \\
\hline & 24 hrs $13 / 7$ & $65 \%$ & 24 hrs $9 / 11$ & $45 \%$ & \\
\hline & 30 hrs $14 / 6$ & $70 \%$ & 30 hrs 11/9 & $55 \%$ & \\
\hline & 48 hrs $15 / 5$ & $75 \%$ & $48 \mathrm{hrs} 10 / 10$ & $50 \%$ & \\
\hline & 55 hrs $16 / 4$ & $80 \%$ & 55 hrs 10/10 & $50 \%$ & \\
\hline & 72 hrs $16 / 4$ & $80 \%$ & & & \\
\hline & 79 hrs $16 / 4$ & $80 \%$ & & & \\
\hline & 96 hrs $16 / 4$ & $80 \%$ & & & \\
\hline Olfactory memory & $7 \mathrm{hrs} 13 / 7$ & $65 \%$ & & & \\
\hline \multirow[t]{4}{*}{$\mathrm{N}=20+20=40$} & 24 hrs $12 / 8$ & $60 \%$ & & & \\
\hline & 30 hrs $12 / 8$ & $60 \%$ & & & \\
\hline & 48 hrs $11 / 9$ & $55 \%$ & & & \\
\hline & 55 hrs $11 / 9$ & $55 \%$ & & & \\
\hline
\end{tabular}

Ants were trained to a green hollow cube or to pieces of thyme set above or aside the meat food. Then, during tests, the numbers of ants giving the correct and the wrong response were counted, and so, the percentage of correct response for the ant population was determined. The percentages obtained for ants consuming nicotine were compared to those obtained for ants having never consumed this alkaloid using the non parametric Wilcoxon test; N, T and P are given, according to the nomenclature of Siegel and Castellan, 1989. These results are graphically presented in Figure 2, upper graphs. * = results obtained by Cammaerts et al., 2011. 

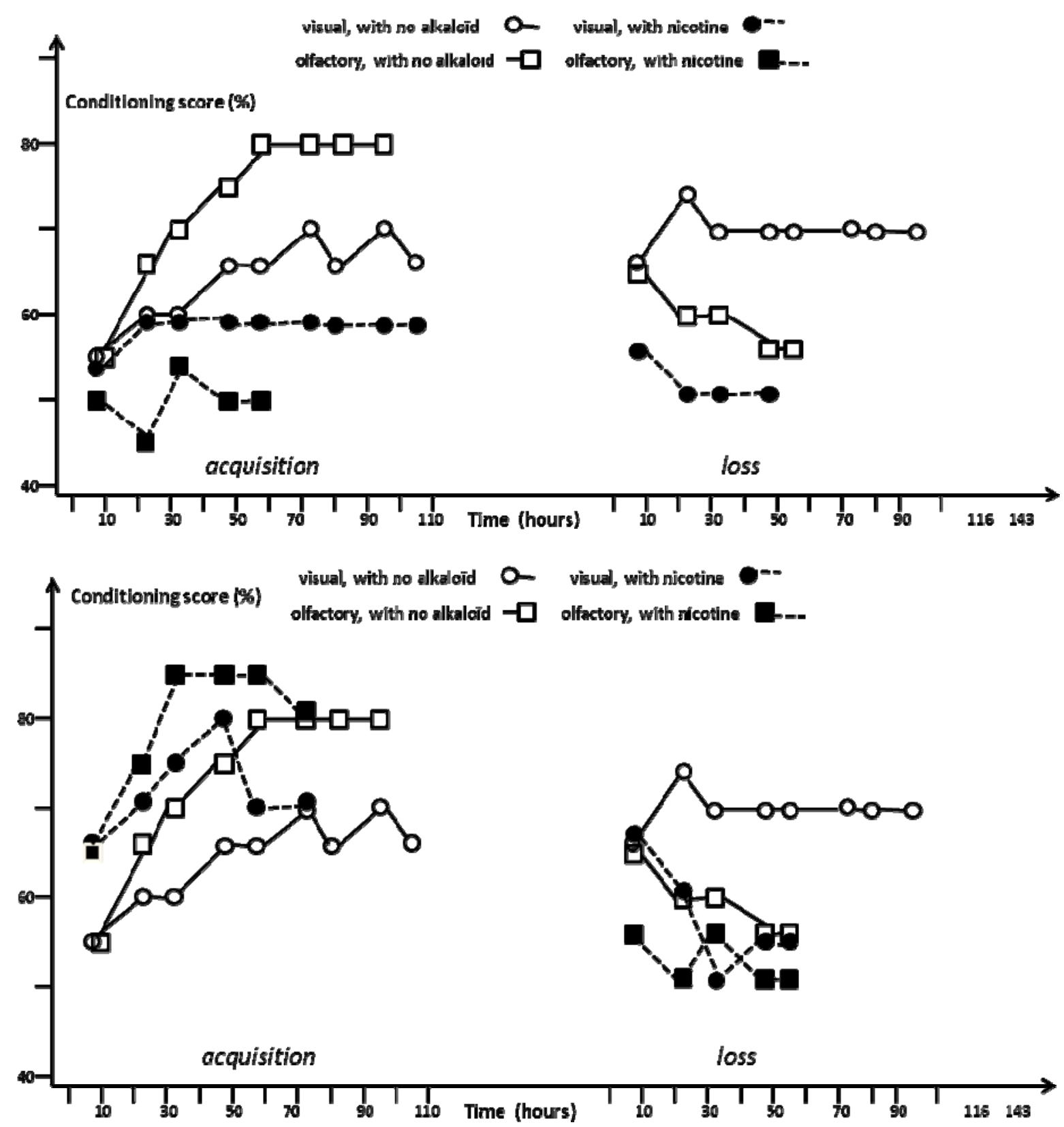

Figure 2. Response of ants conditioned to a visual (circles) or an olfactory (squares) cue, consuming (black forms) or not (empty forms) nicotine, and rewarded with food free of nicotine (upper graphs) or food containing nicotine (lower graphs). Rewarded without nicotine, the ants could scarcely acquire conditioning; rewarded with nicotine, they soon acquired conditioning but retained nearly nothing of it

To conduct a test on a colony, 10 workers of that colony - randomly chosen from the workers of that colony - were transferred one by one to the area at the entrance of the Y-apparatus. Each transferred ant was observed until it turned either to the left or to the right in the Y-tube, and its choice was recorded. Only the first choice of the ant was recorded and this only when the ant was entirely under the cube, i.e. beyond a pencil drawn thin line indicating the entrance of a branch (Figure 1 E, F). Afterwards, the ant was removed and transferred to a polyacetate cup, in which the border was covered with talc, until 10 ants were so tested, this avoiding testing the same ant twice. All the tested ants were then placed back on their foraging area. For each experiment, the numbers of ants, among $10+$ $10=20$, which turned towards the "correct" green (or yellow) cube or thyme (or onion), or went to the "wrong" empty branch of the Y were recorded. The percentage of correct responses for the tested ant population was so established (Tables 2, 4). The results obtained for ants that have consumed nicotine were compared to those 
obtained for ants that have never consumed such a substance using the non parametric test of Wilcoxon (Siegel \& Castellan, 1989, 87-95). For such a test, the value of N, T, and P, according to the nomenclature of the here above cited authors, are given in the results section.

\subsection{Assessment of an Ant'S Ability Requiring No Memory}

This assessment required a) two nests consuming nicotine (we used nests I and II) and two other ones having never consumed this alkaloid (we used nests V and VI, very similar to nests I to IV, collected the same day, on the same field), b) a novel experimental apparatus. This last one, schematically presented in Figure 3 and visible in Figure 1 I, consisted in a small tray $(15 \mathrm{~cm} \times 7 \mathrm{~cm} \times 4.5 \mathrm{~cm})$ inside of which two pieces of white extra strong paper (Steinbach ${ }^{\circledR}, 12 \mathrm{~cm} \times 4.5 \mathrm{~cm}$ ), duly twice folded, were inserted in order to create a maze between a narrow initial space (initial loggia) and a larger area (free area). Two such experimental apparatus were built and used at the same time. Nest I $v s$ nest V, and then nest II $v s$ nest VI were experimented. Each time, for each nest, 15 ants were set in the initial loggia of the apparatus, and those located in this loggia as well as in the free area were counted after 5,10 , 15 and $20 \mathrm{~min}$. The numbers obtained for ants consuming nicotine (nests I and II) were statistically compared to those obtained for ants having never received such an alkaloid (nest V and VI) using the non parametric test of Wilcoxon (Siegel \& Castellan, 1989).

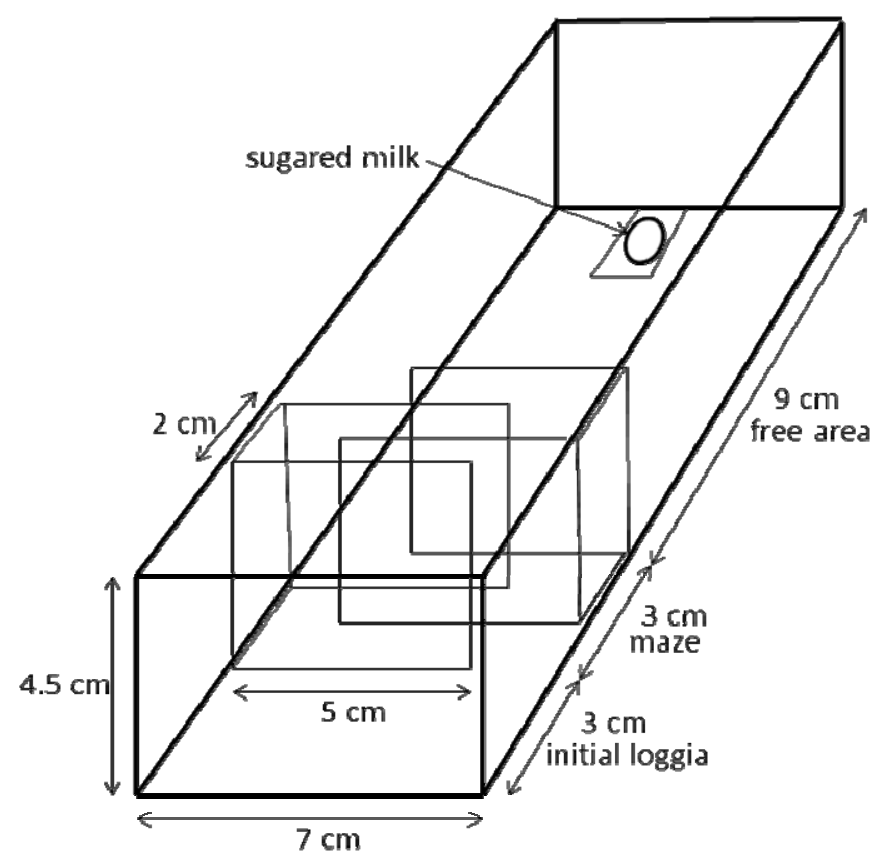

Figure 3. Schema of an experimental apparatus which allows assessing a cognitive ability. Fifteen individuals (e.g. ants) are set in the initial loggia; they tried to escape; the numbers of individuals still in the initial loggia, and those having reached the free area, are counted in the course of time

\subsection{Ants' Habituation to the Consumed Alkaloid}

Four to seven days after ants (of two previously tested colonies) had continuously consumed either the solution of lactose or that of lactose + nicotine, the ants' linear and angular speed were again assessed. The results were compared to those obtained at the beginning of the experiment, after one day of lactose or lactose + nicotine consumption, using the non parametric $\chi^{2}$ test (Siegel \& Castellan, 1989; Table 5, line 1).

\subsection{Ants' Dependence on the Consumed Alkaloid}

After the ants (of colonies I, II, III, IV, because the experiment had to be repeated) had continuously consumed the solution of lactose or that of lactose + nicotine during five to nine days, an experiment was performed to examine if the ants had acquired some dependence on the consumed alkaloid. Each time, fifteen ants were transferred into a small tray $(15 \mathrm{~cm} \times 7 \mathrm{~cm} \times 5 \mathrm{~cm})$, the borders of which had been covered with talc and in which laid two tubes (h $=2.5 \mathrm{~cm}$, diam. $=0.5 \mathrm{~cm}$ ), one containing sugar water, the other sugar water + either lactose or lactose + nicotine (nicotine being at the concentration 1/1,000), the tubes being plugged with cotton (Figure $1 \mathrm{H}$ ). In one of the trays, 
the tube containing the alkaloid was located on the right; in the other tray, it was located on the left. The ants drinking each liquid food were counted 12 times, and the proportion of ants drinking the solution of lactose, or of lactose + nicotine, was established each time (Table 5 , line 2 ). The obtained values were statistically compared to those expected if ants randomly went drinking each kind of food, using the non parametric goodness of fit $\chi^{2}$ test (Siegel \& Castellan, 1989, 45-51).

\subsection{Duration of the Effect of the Alkaloid}

Fourteen days after the ants had continuously consumed the solution of nicotine, the liquid food containing this alkaloid was removed from the ants' tray and replaced by a solution of sugar water + lactose, free of alkaloid. This change was made at a given recorded time. After that, the ants' orientation towards an isolated worker's head was assessed after successive given time periods. The results revealed the decrease of the effects, on ants, of the consumed alkaloid (Table 5, line 3; Figure 4). Their statistical significance could be estimated via the non parametric $\chi^{2}$ test (Siegel \& Castellan, 1989, 111-124). This experiment was not performed on ants fed with the solution of lactose since this solution appeared having no effects on the ants.

\section{Results}

\subsection{Effect on Ants' Locomotion}

Comparatively with ants consuming a solution of lactose, those consuming a solution of lactose + nicotine walked more quickly ( $\left.\mathrm{df}=2, \chi^{2}=13.98, \mathrm{P}<0.001\right)$, and more sinuously $\left(\mathrm{df}=2, \chi^{2}=5.9, \mathrm{P}=0.05\right)$ (Table 1, line 1$)$. This was obvious while testing the ants (Figure $1 \mathrm{~B}$ ).

\subsection{Effect on Ants' Precision when Reacting}

While ants consuming a solution of lactose perfectly oriented themselves towards a source of alarm pheromone, those consuming a solution of lactose + nicotine not well oriented themselves towards such a source (Figure $1 \mathrm{C}$ ). This result was statistically significant ((Table 1 , line $2 ; \mathrm{df}=2, \chi^{2}=13.61, \mathrm{P} \approx 0.001$ ).

\subsection{Effect on Ants' Response to Their Pheromones}

Ants consuming a solution of lactose, as well as those consuming a solution of lactose + nicotine, did not move along a line on which no trail pheromone had been deposited (Table 1, line $3, \mathrm{C}$ (control): $\mathrm{df}=1, \chi^{2}=2.73$, $0.05<\mathrm{P}<0.10, \mathrm{NS})$.

Ants consuming a solution of lactose well followed a trail, meanly moving along about 12 angular arcs. Ants consuming a solution of lactose + nicotine not so well followed such a trail, meanly moving along only about 6 angular arcs (Table 1, line 3, $\mathrm{T}$ (test)). This results was statistically significant $\left(\mathrm{df}=3, \chi^{2}=17.92, \mathrm{P}<0.001\right)$.

\subsection{Effect on Ants' Audacity}

The numbers of ants coming onto a risky apparatus were only slightly, and statistically not significantly, higher after the ants had consumed nicotine for a few days than before they consumed this alkaloid (Table 1, line $4, U=$ $165, \mathrm{Z}=-0.933, \mathrm{P}=0.35$ ). The ants' behavior in front of the apparatus was very similar whatever the presence of nicotine in their sugar food: they hesitated, seldom came onto the apparatus, and soon went away from it.

\subsection{Effect on Ants' Consumption of Food}

Soon after ants consumed nicotine, the numbers of individuals coming onto the meat food, and eating that food, somewhat decreased. The ants did not stop eating; they went on coming on the provided food; but meticulous observations and counts revealed that their food consumption was in fact reduced (Table 1, line 5; $\mathrm{U}=126.5, \mathrm{Z}=$ $1.97, \mathrm{P}=0.05)$.

4.6 Effect on Ants' Visual and Olfactory Conditioning Capability, and on Their Memory, the Reward Being Free of Nicotine

The ants receiving a solution of lactose, and trained to a green cube set above the meat food, acquired a conditioning score of $70 \%$ in $72 \mathrm{hrs}$, and kept that score for more than four days after the cue removal (Table 2, Figue 2). When fed with a solution of lactose + nicotine, the ants, identically trained, reached a score of only $60 \%$ and kept nothing of their conditioning (Table 2, Figure 2). The observed differences were statistically significant (acquisition: $\mathrm{N}=9-3=6, \mathrm{~T}=-21, \mathrm{P}=0.016$; loss: $\mathrm{N}=4, \mathrm{~T}=-10, \mathrm{P}=0.063$ ).

Ants fed with a solution of lactose, and trained to pieces of onion set aside the meat food, reached a conditioning score of $80 \%$ in about $55 \mathrm{hrs}$ (about two days) and, after the cue removal, kept $5 \%$ of their olfactory conditioning (Table 2, Figure 2). After having consumed nicotine, and being submitted to identical conditioning, the ants could never acquire olfactory conditioning (Table 2, Figure 2). This unexpected result was statistically significant $(\mathrm{N}=5$, 
$\mathrm{T}=-15, \mathrm{P}$ 0.031). Given this failure in acquiring conditioning, the ants' olfactory memory under nicotine consumption was not examined.

The results obtained for ants consuming lactose were very similar to those previously obtained on the same species, in similar circumstances, the ants then receiving only sugar water (Cammaerts et al., 2011). The results obtained on ants consuming lactose + nicotine were unexpected, and might be due to the fact that the reward was the meat food, free of nicotine, the green cube and the pieces of thyme being set above or aside the $T$. molitor larva. It was thus check if ants consuming nicotine could present some cognitive ability requiring no memory, in the course of an experiment using no reward, and then, given the result of that checking experiment, conditioning was again tempted on ants consuming nicotine but setting, this time, the visual and the olfactory cues above or aside the sugar food containing nicotine (see the two following paragraphs).

\subsection{Effect on an Ants' Cognitive Ability Requiring no Memory}

When set in the small initial loggia of an adequate apparatus (Figure 1 I, Figure 3), ants having never consumed nicotine stayed there a long time and slowly found their way, through the maze, to the large free area. Among the $15+15=30$ ants set in the initial loggia, 22 were still there after $15 \mathrm{~min}$ and 17 after $20 \mathrm{~min}$, while only 2 and 6 ants were in the free area after the same time periods (Table 3). Ants having consumed nicotine, tested in an identical experimental apparatus, behaved otherwise: they soon found their way through the maze, towards the free large area. Among the $15+15=30$ ants set in the small initial loggia, only 16 were still there after 15 min and 11 after $20 \mathrm{~min}$, while 4 and 10 ants were in the free area after the same time periods (Table 3). Such a result was statistically significant (initial loggia: $\mathrm{N}=8, \mathrm{~T}=36, \mathrm{P}=0.004$; free area: $\mathrm{N}=7, \mathrm{~T}=28, \mathrm{P}=0.008$ ). Given these results, conditioning experiments were reproduced, with other cues of course, placing this time the cue near the food containing nicotine. To save time during which ants consumed nicotine, visual conditioning (to a yellow cube) was tempted on nests III and IV while (at the same time as) olfactory conditioning (to pieces of onion) was conducted on nests I and II (see the following paragraph).

Table 3. Effect of nicotine on a cognitive ability requiring no memory.

\begin{tabular}{|c|c|c|c|c|c|}
\hline \multirow{2}{*}{ Experiment } & \multirow{2}{*}{ Time (min) } & \multicolumn{2}{|c|}{ Nest 4 or 5} & \multicolumn{2}{|c|}{ Nest 1 or 2} \\
\hline & & initial loggia & free area & initial loggia & free area \\
\hline \multirow{4}{*}{$\begin{array}{l}\text { nest } 4 \text { (control) } \\
\text { nest } 1 \text { (nicotine) }\end{array}$} & 5 & 11 & 0 & 6 & 1 \\
\hline & 10 & 12 & 0 & 9 & 1 \\
\hline & 15 & 10 & 2 & 8 & 2 \\
\hline & 20 & 8 & 4 & 7 & 3 \\
\hline \multirow{4}{*}{$\begin{array}{l}\text { nest } 5 \text { (control) } \\
\text { nest } 2 \text { (nicotine) }\end{array}$} & 5 & 13 & 0 & 7 & 5 \\
\hline & 10 & 12 & 0 & 7 & 4 \\
\hline & 15 & 12 & 0 & 8 & 2 \\
\hline & 20 & 9 & 2 & 4 & 7 \\
\hline
\end{tabular}

Ants having never consumed nicotine and ants having done so were tested in the apparatus shown in Figure $1 \mathrm{D}$, and schematically presented in Figure 3. Under nicotine consumption, ants were more able to escape, through a maze, from the small loggia. Details and statistics are given in the text.

\subsection{Effect on Ants' Visual and Olfactory Conditioning Capability, and on Their Memory, the Reward Containing Nicotine}

Under nicotine consumption, ants of nests III and IV, trained to a yellow cube, responded correctly to that visual cue with a score of $65 \%, 70 \%, 75 \%$ and $80 \%$ (this last one having been assessed being blind) after $7 \mathrm{hrs}, 24 \mathrm{hrs}, 30$ hrs and 48 hrs respectively, while ants having never consumed this alkaloid presented the scores of $55 \%, 60 \%$, $60 \%$ and $65 \%$ after the same time periods (Table 4 ). So, under nicotine consumption, ants more rapidly acquired visual conditioning $(\mathrm{N}=6-1=5, \mathrm{~T}=+15, \mathrm{P}=0.031$; Figure 2, lower graphs, acquisition, circles). However, they reached a nearly similar conditioning score (70\%-75\% vs 65\%-70\%). After removal of the visual cue, the ants consuming nicotine more rapidly forgot the learned cue, and retained about $5 \%$ instead of $20 \%$ of their learning (Table 4; $\mathrm{N}=5-1=4, \mathrm{~T}=-10, \mathrm{P}=0.063$; Figure 2, lower graphs, loss, circles). 
Under nicotine consumption, ants of nests I and II, trained to pieces of onion (Figure $1 \mathrm{G}$ ), responded correctly to that olfactory cue with a score of $65 \%, 75 \%, 85 \%$ and $85 \%$ (this last one having been assessed being blind) after 7 hrs, $24 \mathrm{hrs}, 30 \mathrm{hrs}$ and $48 \mathrm{hrs}$ respectively, while ants having never consumed this alkaloid presented the scores of $55 \%, 65 \%, 70 \%$ and $75 \%$ after the same time periods (Table 4 ). So, under nicotine consumption, ants more quickly acquired olfactory conditioning $(\mathrm{N}=6-1=5, \mathrm{~T}=+15, \mathrm{P}=0.031$; Figure 2 , lower graphs, acquisition, squares). But their final conditioning score was only slightly higher $(80 \%-85 \%$ vs $80 \%)$. After the olfactory cue removal, the ants under nicotine consumption more rapidly forgot the learned cue and retained only about $2.5 \%$ (nearly nothing) of their learning (Table 4; $\mathrm{N}=5, \mathrm{~T}=-15, \mathrm{P}=0.031$; Figure 2, lower graphs, loss, squares).

Table 4. Effect of nicotine on conditioning acquisition and on memory, using sugar food (containing nicotine) as a reward

$\left.\begin{array}{lccccc}\hline \text { Studied function } & \multicolumn{3}{c}{\text { no nicotine }} & \text { + nicotine } & \text { statistics } \\ \hline \text { Visual learning ability } & { }^{*} \mathrm{C}: 61 / 59 & 50 \% & & & \\ \mathrm{n}=20+20=40 & 7 \text { hrs } 11 / 9 & 55 \% & 7 \text { hrs } 13 / 7 & 65 \% \\ & 24 \text { hrs } 12 / 8 & 60 \% & 24 \text { hrs } 14 / 6 & 70 \% \\ & 30 \text { hrs } 12 / 8 & 60 \% & 30 \text { hrs } 15 / 5 & 75 \% \\ & 48 \text { hrs } 13 / 7 & 65 \% & 48 \text { hrs } 16 / 4 & 80 \% \\ \text { Visual memory } & 55 \text { hrs } 13 / 7 & 65 \% & 55 \text { hrs } 14 / 6 & 70 \% \\ \mathrm{n}=20+20=40 & 72 \text { hrs } 14 / 6 & 70 \% & 72 \text { hrs } 14 / 6 & 70 \%\end{array}\right] \quad \mathrm{P}=0.031$

Control experiments were those previously made, on ants having never consumed nicotine (column 2 ). Ants having consumed nicotine were then trained to a yellow hollow cube (visual conditioning) or to pieces of onion (olfactory conditioning), these cues being set, this time, above or aside the sugar water containing nicotine. During tests, made in the course of time, the numbers of ants giving the correct response were assessed, and were compared to the control corresponding ones using the non parametric test of Wilcoxon (Siegel \& Castellan, 1989; N, T, P, according to their nomenclature, being given). These results are also shown in Figure 2, lower graphs. 


\subsection{Ants' Habituation to Nicotine}

No habituation was observed, on the ants, to lactose consumption: the ants' locomotion did not change after five days of that sugar consumption (Table 5, line 1; linear speed: $\mathrm{df}=2, \chi^{2}=3.93,0.10<\mathrm{P}<0.20$; angular speed: $\mathrm{df}=3$, $\chi^{2}=4.76,0.10<\mathrm{P}<0.20$ ). Even more, no habituation could be detected, on the ants, to nicotine consumption. The ants' locomotion assessment was made being blind, and very similar values were obtained after five days and after one day of nicotine consumption (Table 5, line 1 ; linear speed: $\mathrm{df}=2, \chi^{2}=1.18,0.50<\mathrm{P}<0.70$; angular speed: $\mathrm{df}=$ $2, \chi^{2}=1.37, \mathrm{P} \approx 0.50$ ). In other words, nicotine soon increased the ants' linear and angular speed, and went on having exactly the same effect after five days of the alkaloid consumption.

Table 5. Habituation to, and dependence on, lactose, and lactose + nicotine; duration of the effects of lactose + nicotine

\begin{tabular}{|c|c|c|}
\hline Effect studied & Variable assessed & Numerical results \\
\hline $\begin{array}{l}\text { Habituation } \\
\text { (after } 7 \text { days) }\end{array}$ & $\begin{array}{r}\text { Lactose: linear speed } \mathrm{mm} / \mathrm{sec} \\
\text { sinuosity ang.deg./cm }\end{array}$ & $\begin{array}{ll}19.0(16.8-20.2) & \text { vs } 1 \text { day: NS } \\
91(84-105) & \text { vs } 1 \text { day: NS }\end{array}$ \\
\hline \multirow{3}{*}{$\begin{array}{l}\text { Dependence } \\
\text { (12 counts) }\end{array}$} & $\begin{array}{r}\text { Lactose }+ \text { nicotine: linear speed } \mathrm{mm} / \mathrm{sec} \\
\text { sinuosity ang.deg. } / \mathrm{cm}\end{array}$ & $\begin{array}{ll}20.3(19.2-22.8) & \text { vs } 1 \text { day: NS } \\
125(106-133) & \text { vs } 1 \text { day: NS }\end{array}$ \\
\hline & $\begin{array}{c}\text { Lactose:choices of sugar water +lactose } v s \\
\text { sugar water }\end{array}$ & $\begin{array}{l}\text { nest } 1: 26 \text { ants vs } 32 \text { ants }=26 / 32=44.8 \% \\
\text { nest 2: } 19 \text { ants vs } 21 \text { ants }=19 / 41=46.3 \%\end{array}$ \\
\hline & $\begin{array}{c}\text { Lactose+nicotine: choice of sugar } \\
\text { water+lactose+nicotine } v s \text { sugar water+lactose } \\
\text { nests I and II: not hungry } \\
\text { choice of sugar water+lactose+nicotine } v s \\
\text { sugar water: nest III, hungry } \\
\text { nest IV, fed up } \\
\text { nest III again, no longer hungry } \\
\text { nest II, starved }\end{array}$ & $\begin{array}{l}\text { nest } 3: 39 \text { ants } v s 14 \text { ants }=39 / 53=73.6 \% \\
\text { nest } 4: 3 \text { ants } v s \quad 6 \text { ants }=3 / 9=33.3 \% \\
\text { nest 3: } 24 \text { ants } v s 23 \text { ants }=24 / 47=51.1 \% \\
\text { nest 2: } 18 \text { ants } v s 0 \text { ants }=18 / 18=100 \%\end{array}$ \\
\hline $\begin{array}{l}\text { Duration of } \\
\text { effect }\end{array}$ & $\begin{array}{l}\text { Lactose+ }+ \text { nicotine: } \\
\text { orientation towards an alarm signal } \\
\text { (angular degrees) in the course of time } \\
\text { control: } 32.0(21.6-56.59)\end{array}$ & $\begin{array}{l}1 \text { hrs: } 69.05(53.4-78.7) \\
3 \text { hrs: } 60.2(51.8-91.9) \\
5 \text { hrs: } 59.5(50.5-63.7) \\
8 \text { hrs: } 61.3(39.9-72.2) \\
11 \text { hrs: } 49.5(34.7-76.2) \\
15 \text { hrs: } 43.4(31.8-61.7) \\
25 \text { hrs: } 35.6(29.8-46.3) \\
29 \text { hrs: } 35.8(26.3-38.5)\end{array}$ \\
\hline
\end{tabular}

Details are given in the text. Briefly, ants did not become habituated to nor dependent on lactose consumption; they did not become habituated to nicotine, and did not become dependent on this alkaloid as long as they felt well but developed dependence as soon as they were hungry or starved. The effects of nicotine sigmoidally decreased in the course of time, ending in about 30 hours. The latter observation is graphically shown in Figure 4, and statistical analysis is reported in the 'Results' section. 


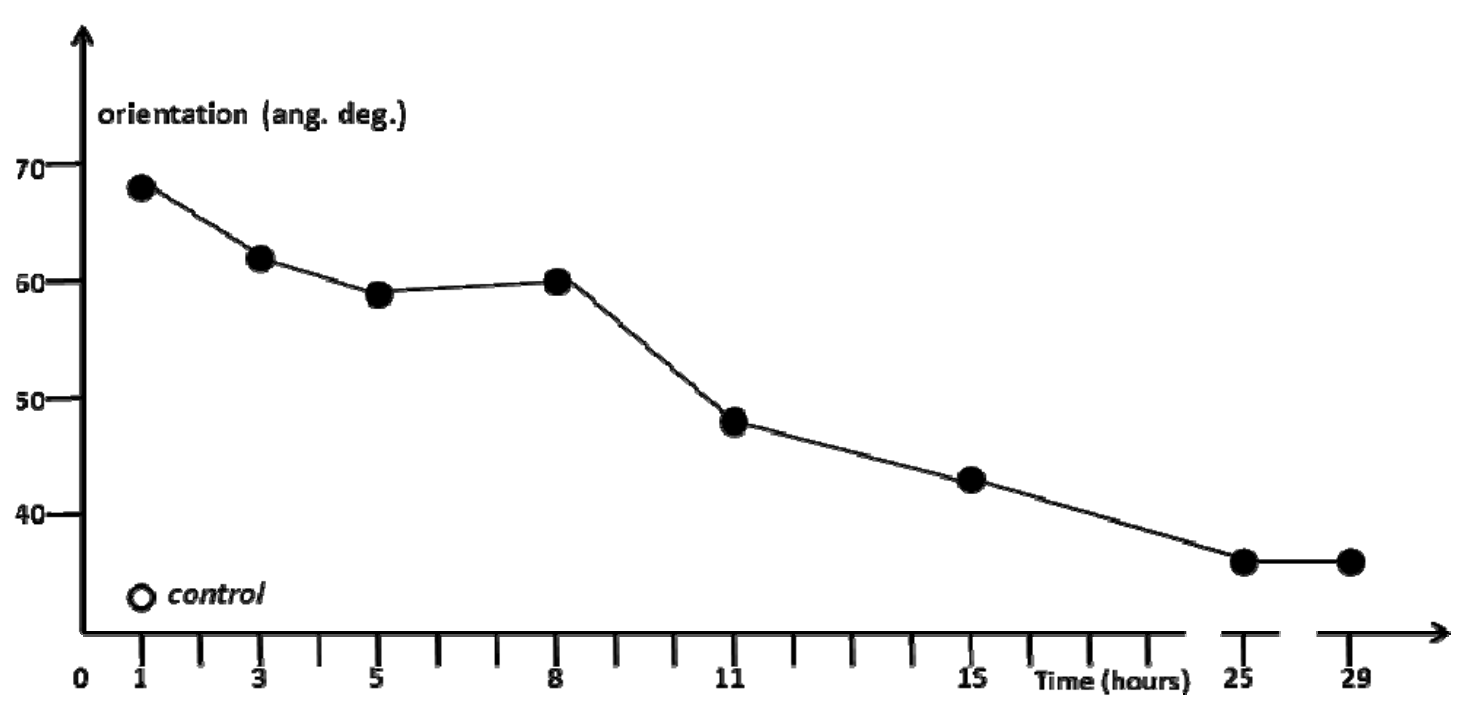

Figure 4. Decrease of the nicotine effects, after its consumption ended. The assessed parameter was the ants' orientation towards an alarm signal, an ethological response affected by the alkaloid consumption. The effects of nicotine first slowly decreased, then, from $8 \mathrm{hrs}$ to $11 \mathrm{hrs}$ after its consumption ended, quickly decreased, and thereafter went on slowly decreasing until a total of about 30 hours. Since the effects of nicotine slowly decreases with time, there is normally no dependence on this alkaloid consumption. But since there is a quick decrease, during a short time, some dependence might develop if, during that time period, there exist(s) any other perturbing factor(s) (f.i. not enough food)

\subsection{Ants' Dependence on Nicotine}

No dependence could be detected on lactose consumption: meanly about $45 \%$ of ants chose this sugar food $v$ food containing no lactose (Table 5, line $2 ; \mathrm{df}=1, \chi^{2}=6.64, \mathrm{P}=0.01$ in favor of sugar water without lactose).

No dependence on nicotine consumption could be detected for ants of nest I and II normally fed: meanly $50 \%$ of the tested ants chose the food containing nicotine, and 50\% that free of the alkaloid (Table 5, line 2). But ants of nest III, tested just before they eat, presented a strong preference for the food containing nicotine: about $73 \%$ of ants chose that food (Table 5 , line $2 ; \mathrm{df}=1, \chi^{2}=11.79, \mathrm{P}<0.001$ ). On the contrary, ants of nest IV, tested just after they had eaten, did not present such a preference: only about $33 \%$ of ants chose the food containing nicotine $(\mathrm{df}=$ $1, \chi^{2}=1,0.30<\mathrm{P}<0.50$ ). Two checking experiments were then performed. Ants of nest III were fed: being no longer hungry, the ants no longer showed any dependence on nicotine consumption: only $51 \%$ of ants chose the food containing the alkaloid (Table 5 , line $2 ; \mathrm{df}=1, \chi^{2}=0.02,0.80<\mathrm{P}<0.90$ ). The ants of nest II were starved for $3 \frac{1}{2}$ days: under starvation, these ants presented a very strong dependence on nicotine: $100 \%$ of the tested ants chose the food containing nicotine (Table 5 , line $2 ; \mathrm{df}=1, \chi^{2}=18, \mathrm{P}<0.001$ ). These results lead to wonder about human's nicotine consumption and dependence.

\subsection{Time Period During Which Consumed Nicotine Affected the Ants}

After ants ended eating nicotine, their precision of reaction - affected by the alkaloid - firstly slowly increased (from 69 to 61 angular degrees) in the course of the first $8 \mathrm{hrs}$. Let us recall that a high value for an orientation means that the orientation is of poor quality. Then, during the following $7 \mathrm{hrs}$, the effects of nicotine rather quickly decreased (from 61 to 43 angular degrees). After that, in the course of the 10 following hours, the alkaloid effects went on slowly decreasing, from 43 to 35 angular degrees (Table 5 , line 3 ). The ants response became statistically similar to that exhibited before consuming nicotine between $8 \mathrm{hrs}$ and $11 \mathrm{hrs}$ after they ended consuming the alkaloid ( $8 \mathrm{hrs:} \mathrm{df}=1, \chi^{2}=6.66, \mathrm{P}=0.01 ; 11 \mathrm{hrs}$ and $15 \mathrm{hrs}$ : $\left.. \mathrm{df}=1, \chi^{2}=2.51,0.05<\mathrm{P}<0.10\right)$. After a total of $29 \mathrm{hrs,}$ the ants' response, e.g. their precision of reaction, was very similar to the control one $\left(\mathrm{df}=1, \chi^{2}=0.11\right.$, $0.70<\mathrm{P}<0.80$ ). During this experiment, it was also observed that the ants' behavior (locomotion, food consumption, trail following) became again usual, identical to that of ants having never consumed nicotine, according to the kinetic revealed by the ants' precision of reaction assessment. So, the effects of nicotine appeared to sigmoidally vanish in the course of time, with a first slow decrease, then a short, rather rapid one, and finally again a slow decrease (Figure 4). 


\section{Discussion}

\subsection{Synopsis}

Nicotine, present in Solanaceae plants, is one of the most consumed alkaloid in the word. All its effects are not entirely researched, understood and/or revealed; even its lethal dose is yet under discussion (Mayer, 2013). Presuming that ants could be used as biological models, we looked for the effects of nicotine using the ant Myrmica sabuleti, a very well known species, as a biological model. The experimental work showed that nicotine:

— increases the ants' linear and angular speed, so in fact, the animals' general activity

— reduces the ants' precision of response (i.e. their orientation towards an alarm signal)

- decreases their response to their pheromones (i.e. their trail following behavior)

— does not affect their audacity

— reduces their food consumption

— largely reduces their learning ability if they are rewarded with food free of nicotine

— increases their cognitive ability in navigating through a maze

— increases their rapidness in acquiring visual or olfactory conditioning if they are rewarded with food containing nicotine

— does not valuably increase their visual and olfactory conditioning score

— decreases the time during which they retain a learned cue

— impacts their visual and their olfactory memory

- does not lead to habituation

- does not lead to dependence if the insects feel well, need nothing

— leads to dependence as soon as the individuals feel no longer well or are deprived of something (for instance of food)

— presents a sigmoid decrease of its effects, in about $25 \mathrm{hrs,} \mathrm{with} \mathrm{a} \mathrm{slow,} \mathrm{then} \mathrm{a} \mathrm{short} \mathrm{quick,} \mathrm{then} \mathrm{again} \mathrm{a} \mathrm{slow}$ decrease of its effects.

\subsection{Discussion}

Remarks must now be made about some experimental protocols, and then several results will be discussed.

\subsubsection{Remarks about Some Experimental Protocols}

- a total of 30 experiments were conducted. To do so, we used five large colonies, and performed each experiment on at least 10 to 20 individuals. First, the five used colonies were identical: they were collected the same day, on the same field, and were identically maintained in the same laboratory; they were demographically very similar. Secondly, nicotine somewhat impacted the ants' survival: after a few weeks, the ants appeared tired; they often slept, and were agitated in the mean time. We so minimized the amount of colonies and ants used. Our samples were not very large, though being not too small comparatively with common ethological studies. Of course, according to our sample size and the not Gaussian character of the obtained distributions of values, we used non parametric statistics for analyzing our results.

- pure nicotine could be obtained only mixed to lactose. We so made controls with lactose what allowed confirming previous results (for instance, the kinetics of the ants' acquisition and loss of visual and olfactory conditioning, their positive orthokinesis towards a source of alarm pheromone ...) and showing that lactose has no detectable effects on the animals.

- attention have been taken about the fact that, once animals have been conditioned to a given cue, they are no longer naïve for that cue. We so adequately used different but similar ant colonies or cues.

- we are perfectly conscious that ants are no mammals, and that experiments on ants could only be a first, cheap, easy, quick step of any further pharmacological or medicinal researches. 


\subsubsection{Discussion of Several Results}

- we obtained, on ants, no habituation at all to nicotine consumption. This results was obtained being blind, on 20 ants, and was highly significant. Note that if habituation exists for some drugs, it can easily be reveal by experimenting on ants (i.e. habituation exists for cocaine and was revealed by tests on ants: Cammaerts et al., 2014). This means that, normally, no larger amount but identical amount of nicotine should be consumed for obtaining the same physiological and ethological effects. If larger amounts are consumed, progressively, in the course of time, the cause is not habituation to nicotine; but another one.

- an important result is that ants consuming nicotine never acquired valuable conditioning as long as the provided reward was free of nicotine. When the reward contained nicotine, the ants could acquire conditioning, and they acquired conditioning more quickly than usually. This means that, under nicotine consumption, what is commonly considered as being a reward (f.i. food) is no longer so considered. The only valuable reward is become the nicotine, itself. This result obtained on ants is in agreement with what occurs for human beings: nicotine replaces acetylcholine in the brain, and so induces feeling well-being (see the introduction). Consequently, ants are really good biological models, and individuals consuming nicotine may be deprived from many normally rewarding elements.

- during our experimentation, nicotine appeared to increase individuals' cognitive abilities. The experiment lasted only $20 \mathrm{~min}$. So, in fact, the individuals consuming nicotine solved more quickly the problem than those having never consumed this alkaloid. This also occurred during the conditioning experiment: under nicotine consumption, the individuals did not really reach better score, they only reached the score more rapidly, and, having been quick in making the task, they retained less of what they had learned. On the basis of our experiments, we presume that the usually admitted enhancement of cognition due to nicotine may be punctual, momentarily, and not persistent. In other words, nicotine might momentarily enhance some cognitive abilities, but might, in fine, reduce the memorization of acquired knowledge.

- ants, in a normal physiological and ethological state, did not present any dependence on nicotine. But as soon as they no longer were in good state, they immediately developed dependence. Ants seemed thus suitable biological models for pointing out potential dependence. Nicotine may be 'in the nick' of inducing dependence; some abnormality, some need, some privation, and perhaps some compounds, could soon confer to nicotine the faculty of inducing dependence. This result may explain the mixed conclusions of researchers on the subject (Benowitz, 1996).

- nicotine leads to no habituation, and to no dependence, and its effects slowly decease in the course of time after its consumption ends. This confirms a previous observation (Cammaerts et al., 2014): no dependence occurs when there is no habituation to the 'drug', and when its effects slowly decrease with time.

- though decreasing slowly, in about $25 \mathrm{hrs,} \mathrm{the} \mathrm{effects} \mathrm{of} \mathrm{nicotine} \mathrm{however} \mathrm{present} \mathrm{a} \mathrm{rather} \mathrm{quick} \mathrm{decrease}$ between $8 \mathrm{hrs}$ and $15 \mathrm{hrs}$ after this alkaloid consumption ended. This rather quick decrease, which lasts about 7 hrs, might be perceived by nicotine consumers, and might induce dependence in individuals exposed, during this short time period, to any other perturbing situations.

- under nicotine consumption, ants' food consumption largely decreased. This is in agreement with the fact that food free of nicotine is no longer considered as a reward, as a beneficial or pleasant element. Such a result is objective since obtained on ants, naïve about the conducted experimentation. People consuming nicotine often eat less. This is in favor of the use of ants as biological models.

\subsection{Conclusion}

A final conclusion should now be tempted to be advanced. Small amounts of nicotine do not imperil the survival of the individuals, but yet have adverse effects. The alkaloid increases, without usefulness, the agitation, the excitation; it decreases the precision of response, the food consumption, the memory, while apparently (since only momentarily) increasing the cognitive abilities. No habituation occurs. No dependence normally appears except if the individuals do not feel fully well. Nicotine acts in place of rewarding elements, and so deprives the individuals of usual pleasant elements. All these cumulated effects, essentially if large amount of the alkaloid is consumed, finally impact the individuals' health. These physiological and ethological effects, revealed on ants, are in agreement with those actually known for nicotine. Findings on ants are more objective, more precise, brings explanation and even suggest solution (i.e. results about habituation, decrease of the effects, impact on cognition, occurrence of dependence, dependence could be suppressed by feeding the ants). On the basis of our experimentation, we might cautiously advance some advices. Eventually, addition of nicotine in the consumed food may stop the decrease of food consumption; several very rewarding elements may be taken, progressively, 
instead of nicotine; any need, lack, problem should be solved. Doing so, very probably, nicotine consumption will decrease in the course of time, and dependence on nicotine will vanish. In any way, it can be deduced, from the present work, that ants - i.e. very well known ant species - could be used, in a first step, for studying physiological and ethological effects of compounds, treatments, or factors.

\section{Acknowledgements}

We sincerely thank Dr R. Cammaerts who applied the Mann-Whitney U tests for us, and helped us during the most time consuming experiments.

\section{References}

Abramson, C. I., Wells, H., \& Janko, B. (2007). A social insect model for the study of ethanol induced behavior: the honey bee. In R. Yoshida (Ed.), Trends in Alcohol Abuse and Alcoholism Research (pp. 197-218). Nova Sciences Publishers, Inc.

Andre, R. G., Wirtz, R. A., \& Das, Y. T. (1989). Insect Models for Biomedical Research. In A. D. Woodhead (Ed.), Nonmammalian Animal Models for Biomedical Research. Boca Raton, FL: CRC Press.

Benowitz, N. L. (1996). Pharmacology of Nicotine: Addiction and Therapeutics. Annual Review of Pharmacology and Toxicology, 36, 597-613. http://dx.doi.org/10.1146/annurev.pa.36.040196.003121

Billen, J., \& Morgan, E. D. (1998). Pheromone communication in social insects - sources and secretions. In R. K. Vander Meer, M. D. Breed, K. E., Espelie, \& M. L. Winston (Eds.), Pheromone Communication in Social Insects : Ants, Wasps, Bees, and Termites (pp. 3-33). Boulder, Oxford: Westview Press.

Cammaerts, M. C. (2007). Colour vision in the ant Myrmica sabuleti MEINERT, 1861 (Hymenoptera: Formicidae). Myrmecological News, 10, 41-50.

Cammaerts, M. C. (2012). Navigation system of the ant Myrmica rubra (Hymenoptera, Formicidae). Myrmecological News, 16, 111-121.

Cammaerts, M. C. (2013a). Ants' learning of nest entrance characteristics (Hymenoptera, Formicidae). Bulletin of Entomological Research, 6. http://dx.doi.org/10.1017/S0007485313000436

Cammaerts, M. C. (2013b). Learning of trail following behaviour by young Myrmica rubra workers (Hymenoptera, Formicidae). ISRN Entomology.

Cammaerts, M. C. (2014). Performance of the species-typical alarm response in young workers of the ant Myrmica sabuleti is induced by interactions with mature workers. Journal of Insect Sciences (in press).

Cammaerts, M. C. (ND). Learning of foraging area specific marking odor by ants (Hymenoptera, Formicidae). Journal of Entomological Research (in press).

Cammaerts, M. C., \& Cammaerts, D. (2014). Comparative outlook over physiological and ecological characteristics of three closely-related Myrmica species. Biologia, 69 (in press).

Cammaerts, M. C., \& Gosset, G. (2014). Impact of age, activity and diet on the conditioning performance in the ant Myrmica ruginodis used as a biological model. International Journal of Biology, 6(2), 10-20.

Cammaerts, M. C., \& Nemeghaire, S. (2012). Why do workers of Myrmica ruginodis (Hymenoptera, Formicidae) navigate by relying mainly on their vision? Bulletin de la Société Royale Belge d'Entomologie, 148, 42-52.

Cammaerts, M. C., \& Rachidi, Z. (2009). Olfactive conditioning and use of visual and odorous elements for movement in the ant Myrmica sabuleti (Hymenoptera, Formicidae). Myrmecological news, 12, 117-127.

Cammaerts, M. C., Morel, F., Martino, F., \& Warzée, N. (2012b). An easy and cheap software-based method to assess two-dimensional trajectories parameters. Belgian Journal of Zoology, 142, 145-151.

Cammaerts, M. C., Rachidi, Z., \& Cammaerts, D. (2011). Collective operant conditioning and circadian rhythms in the ant Myrmica sabuleti (Hymenoptera, Formicidae). Bulletin de la Société Royale Belge d'Entomologie, $147,142-154$.

Cammaerts, M. C., Rachidi, Z., \& Gosset, G. (2014). Physiological and ethological effects of caffeine, theophylline, cocaine and atropine; study using the ant Myrmica sabuleti (Hymenoptera, Formicidae) as a biological model. International Journal of Biology, 3, 64-84.

Cammaerts, M. C., Rachidi, Z., Beke, S., \& Essaadi, Y. (2012a). Use of olfactory and visual cues for traveling by the ant Myrmica ruginodis (Hymenoptera, Formicidae). Myrmecological News, 16, 45-55. 
Cammaerts, M. C., Rachidi, Z., Bellens, F., \& De Doncker, P. (2013). Food collection and response to pheromones in an ant species exposed to electromagnetic radiation. Electromagnetic biology and medicine, 32(3), 315-332. http://dx.doi.org/10.3109/15368378.2012.712877

Cammaerts-Tricot, M. C. (1973). Phéromone agrégeant les ouvrières de Myrmica rubra. Journal of Insect Physiology, 19, 1299-1315.

Deutsch, J. (1994). La drosophile: des chromosomes aux molécules. John Libbey Eurotext.

Devineni, A. V., \& Heberlein, U. (2013). The evolution of Drosophila melanogaster as a model for alcohol addiction. Annual Review of Neurosciences, 36, 121-138. http://dx.doi.org/10.1146/annurev-neuro-062012-1 70256

Døring, T. D., \& Chittka, L. (2011). How human are insects and does in matter? Formosan Entomologist, 31, 85-99.

Frenk, H., \& Dar, R. (2005). Dépendance à la nicotine: critique d'une théorie. préface du Pr Robert Molimard, Paris, Belles Lettres, traduction de $A$ critique of nicotine addiction, Kluwer, 2000.

Hölldobler, B., \& Wilson, E.O.. (1990). The ants. Harvard University Press, Springer-Verlag Berlin.

Keller, L., \& Gordon, E. (2006). La vie des fourmis. Odile Jacob, Paris.

Keller, R. A. (2011a). A phylogenetic analysis of ant morphology (Hymenoptera: Formicidae) with special reference to the Poneromorph subfamilies. Bulletin of the American Museum of Natural History, 355, 99.

Keller, R. A. (2011b). Ants protect their mouthparts by locking them in place. Colloque organized at Banyuls/mer.

Kolb, B., \& Whishaw, I. Q. (2002). Neuroscience \& cognition: cerveau et comportement. New York, Basing Stoke: Worth Publishers.

Mayer, B. (2013). How much nicotine kills a human? Tracing back the generally accepted lethal dose to dubious self-experiments in the nineteenth century [archive], Archives of Toxicology. http://dx.doi.org/10.1007/s0020 4-013-1127-0

Passera, L. (2006). La véritable histoire des fourmis. Librairie Fayard.

Passera, L., \& Aron, S. (2005). Les fourmis: comportement, organisation sociale et évolution. Les Presses Scientifiques du CNRC, Ottawa, Canada.

Russell, W. M. S., \& Burch, R. L. (2014). The Principles of Humane Experimental Technique. Johns Hopkins University

Siegel, S., \& Castellan, N. J. (1989). Nonparametric statistics for the behavioural sciences. McGraw-Hill Book Company, Singapore.

Waldum, H. L., Nilsen, O. G., Nilsen, T., Rørvik, H., Syversen, V., Sanvik, A. K., .. Brenna, E. (1996). Long-term effects of inhaled nicotine. Life Science, 58, 1339-1346. http://dx.doi.org/10.1016/0024-3205 (96)00100-2.

Wehner, R., \& Gehring, W. (1999). Biologie et physiologie animales. De Boek Université, Thieme Berlag, Paris, Bruxelles.

\section{Copyrights}

Copyright for this article is retained by the author(s), with first publication rights granted to the journal.

This is an open-access article distributed under the terms and conditions of the Creative Commons Attribution license (http://creativecommons.org/licenses/by/3.0/). 